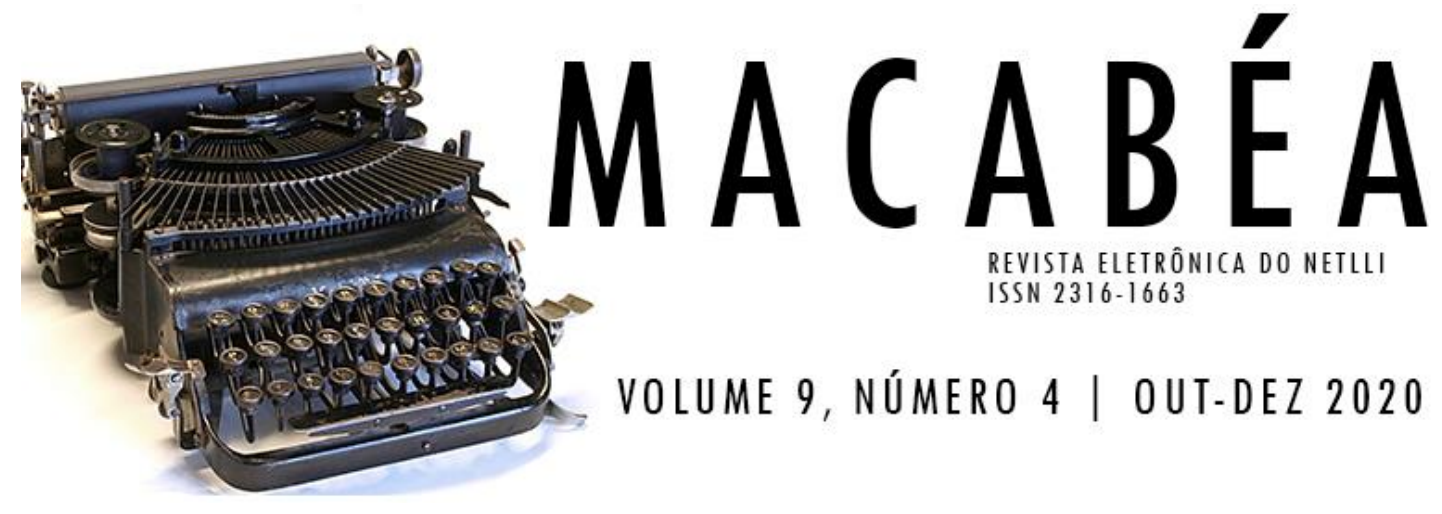

\title{
O POETA DAS COISAS PEQUENAS: A TRAJETÓRIA DE MANUEL BANDEIRA
}

THE POET OF SMALL THINGS: THE TRAJECTORY OF MANUEL BANDEIRA

VALDEMAR VALENTE JUNIOR UNIVERSIDADE ESTÁCIO DE SÁ, BRASIL

\author{
RESUMO | INDEXAÇÃO | TEXTO | REFERÊNCIAS | CITAR ESTE ARTIGO | 0 AUTOR \\ RECEBIDO EM 09/07/220 • APROVADO EM 19/08/2020
}

\section{Abstract}

This article aims to identify the various elements that make up Manuel Bandeira's poetic work as essential references to modern Brazilian culture. In this sense, it is necessary to resort to the chronological aspect of life and the work of those who cling to the meaning of reconstructing of the smallest things in order to disperse as a reason for the poetry he writes. In view of this, the exercise of poetry represents the possibility of repairing what was broken, like the tuberculosis with which he lives from adolescence to old age. Likewise, it is up to Manuel Bandeira, as a pioneer of Modernism, to give up this place to cross sucessive literary movements over time, imposing the seal of his enormous talent. In view of this statement, it is worth considering its capacity of contribute to a kind of permanent renewal of Brazilian poetry.

\section{Resumo}

0 presente artigo tem por objetivo identificar os vários elementos que compõem a obra poética de Manuel Bandeira como referências essenciais à cultura brasileira moderna. Nesse sentido, se faz preciso recorrer ao aspecto cronológico da vida e da obra de quem se apega ao significado de reconstrução das coisas 
ínfimas em via de se dispersarem como razão de ser da poesia que escreve. Diante disso, o exercício da poesia representa a possibilidade de consertar o que se quebrou, a exemplo da tuberculose com a qual convive da adolescência à velhice. Do mesmo modo, cabe a Manuel Bandeira, na condição de pioneiro do Modernismo, abrir mão desse lugar para atravessar os sucessivos movimentos literários ao longo do tempo, impondo a chancela de seu enorme talento. Em vista dessa afirmação, pode ser pensada sua capacidade de contribuir para uma espécie de renovação permanente da poesia brasileira.

\section{Entradas para indexação}

KEYWORDS: Manuel Bandeira. Brazilian literature. Modern poetry. Poetic creation. Literary movements.

PALAVRAS-CHAVE: Manuel Bandeira. Literatura Brasileira. Poesia moderna. Criação poética. Movimentos literários.

\section{Texto integral}

\section{PENUMBRSMO E MODERNISMO}

No transcurso de criação da poesia brasileira, talvez não exista outra vocação tão efetiva para os misteres do fazer poético que a de Manuel Bandeira. Na condição de quem consegue superar os empecilhos de uma vida de vicissitudes, a que parece condenado, se impõe a marca de sua poesia, sendo este o remédio que a vida lhe oferece para aliviar os seus males. Tuberculoso desde a adolescência, o poeta chega à velhice tendo como forma de suportar o tempo que se impõe como um desafio a poesia em suas instâncias de dor e prazer como uma das mais legítimas afirmações do que representa ser poeta. A tuberculose que lhe ameaça a existência ainda muito cedo, acaba por se tornar uma aliada como quem o poeta convive até o fim da vida. Diante disso, os primeiros sinais de uma poética que tenderia a seguir diversos caminhos têm início com uma tendência que se efetiva a partir do Pós-Simbolismo, também chamado de Penumbrismo, espaço sombrio onde poetas como Ribeiro Couto, Olegário Mariano e Guilherme de Almeida também buscam abrigo, a partir de um jogo de luz e escuridão que atua como sucedâneo às formas do Simbolismo, antecedendo o Modernismo:

Os dois primeiros livros de Manuel Bandeira formam um conjunto quase uniforme, dada a similaridade de suas característica: predominância de traços penumbristas acrescidos da "máscara", em Carnaval; regularidade de composição, quebrada por algumas inovações formais; alguns poemas anunciadores do modernismo, pelo seu ritmo liberado e pela linguagem simples (antirretórica); presença de características que particularizarão o poeta em sua produção posterior: tratamento especial da temática do 
quotidiano; aceitação e alegria de viver; tom irônico. (GOLDSTEIN, 1983, p. 110).

Assim, a estreia de Manuel Bandeira com A cinza das horas (1917) antecede o Modernismo, atendendo às queixas que o poeta alimenta com relação à sua existência desditosa. Desse modo, não se constitui em exagero pensar a respeito de uma poesia que se exercita em semitons de natureza simbolista, exprimindo sua melancolia em poemas como "Desalento" e "Desencanto". Esses poemas expressam a emoção de quem busca reunir o que se dispersou, recolhendo os destroços das coisas que se quebram, a exemplo de sua saúde frágil, a que se faz preciso ater-se com cuidado. Diante disso, a estreia em A cinza das horas, embora recorrendo às tonalidades de uma dicção de sonoridade simbolista, caracteriza um estilo que se estende até o final de sua vida. Manuel Bandeira confirma em sua obra a opção pela fragilidade das coisas mínimas que correm o risco da dispersão e da perda, a exemplo de uma existência marcada pela doença e pela incerteza do dia vindouro. Assim, se faz preciso ter cuidado com a vida, do mesmo modo que com as palavras de que dispõe ao executar a difícil tarefa de dar sentido aos estragos que o tempo lhe impôs de modo decisivo.

Em seguida, sua adesão ao Modernismo, na ocasião em que, mesmo ausente, tem o seu poema "Os sapos" declamado por Ronald de Carvalho, na Semana de Arte Moderna, representa a tomada de posição do poeta maduro e consciente que percebe a mudança que rege o princípio básico da poesia desse momento. Em vista disso, assume uma posição de confronto com relação à vigência de posturas conservadoras, satirizando a poesia parnasiana através do ritmo martelado do canto dos sapos como sinônimo de um estilo sem alternâncias ou sugestões. 0 Parnasianismo, portanto, se torna emparedado em suas opções temáticas e construtivas, convertendo-se no alvo predileto de que os modernistas se servem para criticar seu espírito passadista e conservador. 0 escândalo provocado pelas repetições onomatopaicas do poema, em sua apresentação no Teatro Municipal de São Paulo, se fez suficiente para que a posição de Manuel Bandeira se imponha como elemento que esgarça ainda mais a relação entre modernistas e parnasianos:

Desde A cinza das horas, publicado em 1917, Manuel Bandeira perturba nosso concerto literário. Dois anos depois, em Carnaval, sua voz faz-se satirizante com 'Os sapos', poema que seria uma espécie de hino nacional dos modernistas. Quando esses surgem, por volta de 1921, já lá encontram o poeta em seu perau profundo. Muitos procuram afinar a voz pela dele e todos lhe reconhecem o mérito da primazia. (HOLANDA, 1980. p. 142-157).

Por conta disso, o surgimento de Carnaval (1919) dá conta de uma tomada de posição que reflete a dimensão crítica do Modernismo como sinal de desconstrução em relação à tradição. Assim, poemas como "Os sapos" e "Bacanal" 
dão conta da ruptura que o Modernismo apresenta como sinal da nova estética que passa a ter efeito. Situado na fresta que se mostra como um espaço possível de atuação, por sua condição de obra que busca a recuperação do que se mostra disperso, a poesia de Manuel Bandeira incide na falta de pressa de quem desconhece o amanhã. Por isso, seus poemas correspondem a um tipo de artesanato que se aproveita de vários materiais que se dispersam. Esses materiais, por sua vez, encontram-se no rol das coisas sem maior importância, sendo por ele aproveitadas como meio de assegurar sua presença na vida e na poesia. Assim, poemas como "Debussy" e "Hiato" têm como significado a relação mínima com as coisas mais simples, a partir de uma voz que soa em uma espécie de semitom, marcando quase sempre a relação do poeta com o mundo que o cerca. Em vista disso, a festa que se celebra em Carnaval decorre de um evento de que é apenas um observador, uma vez que seu distanciamento oferece excelentes resultados.

Em seguida, Ritmo dissoluto (1924), como seu próprio título sugere, estabelece o rompimento com a métrica tradicional quando Manuel Bandeira expõe sua fragilidade de tuberculoso tentando recompor o sentido das coisas que se quebram sem que para elas haja conserto. São esses os exemplos dos poemas "Meninos carvoeiros' e "Gesso", que tematizam a relação do poeta com os seres e coisas diminutas, e que se fragilizam sem que haja qualquer possibilidade de remissão para sua perda completa. Assim, o poeta mal curado da tuberculose que o acompanha como um estigma capaz de lhe fornecer material para a poesia da vida inteira, encontra em Ritmo dissoluto a medida correta. Para esse fim, concorre uma poesia que se faz expressar a partir de um tom coloquial, a exemplo de "Balada de Santa Maria Egípcia" e "Na solidão das noites úmidas", quando uma sonoridade bucólica que se faz perceber na quebra do ritmo poético. Isso o aproxima do discurso coloquial que oferece a verso uma nova tonalidade, afastando-se da herança clássica e romântica que ainda carrega consigo, preservando-a como termo que irá recuperar em outras ocasiões, não obstante sua condição de modernista:

Esta aderência do escritor a temas de sua realidade imediata e do mais 'humilde cotidiano' significa, antes de mais nada, uma conquista de liberdade de criação, com relação à obrigatoriedade convencional, anteriormente dominante, dos temas considerados de antemão poéticos. Mas a aproximação ao prosaico e à realidade misturada do cotidiano onde o poeta pode de repente detectar o sublime da poesia, conduz à utilização de uma nova técnica poética: o verso livre. (ARRIGUCCI JR., 2003, p. 54).

0 ponto alto de sua presença no Modernismo concorre para que Libertinagem (1930) assuma essa medida. Nessa obra, "Evocação do Recife" e "Vou-me embora pra Pasárgada" tornam-se poemas destacados na poesia de Manuel Bandeira, uma vez que assumem uma dicção que servirá doravante como diapasão de uma obra que efetivamente chega à maturidade. Essa obra configura-se como termo decorrente, não apenas do conteúdo intelectual de quem a escreve, mas, do 
mesmo modo, dos sucessivos embates do poeta com sua saúde fragilizada. Diante disso, poemas como "Não sei dançar" e "Pneumotórax" dão conta de uma relação que se estabelece entre o poeta e o sofrimento que tangencia a ironia, quando a passividade diante da festa de Carnaval de que não pode tomar parte, na condição de tísico sem remissão, é a mesma do doente diante de um médico que constata o irremediável estrago em seus pulmões. Para além da ironia com que recebe a dor e o sofrimento de uma vida que se converte em poesia, Manuel Bandeira põe em prática sua observação crítica em "Poética", quando comenta com elevada dose de rigor o momento que observa na poesia brasileira:

O lirismo namorador / raquítico / sifilítico compõe um conjunto que tem sua referência na temática romântica. 0 poeta questiona aqui alguns dos motivos mais utilizados por nossos românticos, o amor inconsequente, o patriotismo, o estado doentio (BRANDÃO, 1987, p. 22-28).

O que representa sua escrita poética, do jogo de luz e sombra de sua estreia com $A$ cinza das horas ao discurso estilhaçado de Libertinagem, parece encerrar um ciclo referente ao amadurecimento, não apenas de uma produção poética em particular, mas, do mesmo modo, na atuação de uma geração que ganha novo folego. As conquistas formais da primeira fase modernista chegam ao seu final, dando lugar a um dos momentos mais ricos da criação poética brasileira. Por conta disso, Estrela da manhã (1926) concorre como termo que aprofunda uma poética que ainda pode representar o programa modernista em sua fase mais radical de reação ao Parnasianismo. Nesse sentido, a diluição do discurso alia-se ao tom coloquial que assume em "Balada das três mulheres do sabonete Araxá" e "Tragédia brasileira". Em ambos, os aspectos de oralidade perpassam a escrita dando-lhe o foro de narrativa, o que concorre para que se tenha a dissolução completa da configuração do verso em seu esquema tradicional. No primeiro exemplo, um simples rotulo de sabonete transforma-se em peça de elevado valor poético. No segundo, a começar pelo título, a tragédia, entendida como referência ao gênero clássico, converte-se em uma espécie de crônica jornalística que expõe a miséria cotidiana como elemento inerente à desconstrução modernista em sua plena atividade.

\section{A DICÇÃo DEFINITIVA}

A consagração de Manuel Bandeira como personalidade definitiva da poesia brasileira parece ter chegado com Lira dos cinquent'anos (1944), onde se pode verificar uma mudança significativa no que representou para o poeta não apenas o convívio com a tuberculose, mas, do mesmo modo, a necessidade de colocar a plataforma modernista em dia. Isso decorre das transformações na obra de quem, mesmo em face desse momento diluição, situa-se como poeta conhecedor da tradição em todos os seus períodos. Assim, Manuel Bandeira não assume outra 
posição que não seja a de seguir a corrente em curso, na medida em que já não se faz obrigatória a experimentação modernista como sinônimo dos movimentos da vanguarda europeia. Diante disso, Lira dos cinquent'anos não se furta a recorrer ao que de certo modo representa, por exemplo, a tradição do soneto, ainda que a isso se imponha um processo de revitalização do ritmo dessa forma de poesia. Isso concorre para que essa fase se inscreva como instância que se descola da relação que os modernistas estabelecem com uma dependência daquilo que os fundamentou em seu primeiro instante. A sequência de criação da poesia moderna, portanto, parece seguir a vocação a que cada poeta tem consigo, não importando mais o receituário de vanguarda como sinônimo de uma atualização que efetivamente já tivera lugar:

A busca de um conteúdo brasileiro para a criação artística, revestindo de originalidade, pela primeira vez, em conjunto, tudo o que as letras proporcionassem, teria de completar-se com a elaboração da língua literária, capaz de refletir e traduzir a rica temática nacional. (SODRÉ, 1969, p. 528).

A sequência que se pode observar na poesia de Manuel Bandeira diz respeito à enorme vocação de quem não mais necessita comprovar seu talento. Na condição de poeta crítico, sua obra tende a assumir aspectos se sobriedade e equilíbrio, o que se pode constatar em Belo, belo (1948), a partir do momento em que recorre a uma musicalidade que difere da dissonância do jazz-band em um baile de terça-feira gorda. Nesse novo momento, o poeta recorre a temas que fogem ao que a poesia modernista propugna, a exemplo de "Sextilhas românticas", ou ainda, "Letras para uma valsa romântica", quando se mostra desinteressada em seguir seu receituário. Isso decorre da dilaceração das formas tradicionais que se mostram extremamente importantes à configuração de uma obra que se avoluma com o passar do tempo. Não obstante a sobriedade que reitera a influência que recebe das formas universais da poesia, Manuel Bandeira ainda encontra folego para tratar da questão social com elevada dose de sarcasmo, a exemplo de "0 bicho", na ocasião em que constata a tragédia humana decorrente da exclusão e da miséria. Mais ainda, recorre ao jogo de luz e sombra que evoca sua condição de tísico sem remédio em "Vida noturna", além de brincar com as palavras em "Neologismo", quando retoma o poema-piada tão valioso ao Modernismo em sua primeira fase.

Seguem-se a Belo, belo as publicações de Opus 10 (1952) e Estrela da tarde (1960), que do mesmo modo parecem reiterar a opção pela construção de formas e pela efetivação de ritmos. Isso resulta de uma dicção que se mostra em sua feição definitiva. Daí em diante, se estabelece um lugar patente, em vista da posição de um poeta afeito a muitas batalhas que parece ter dado o melhor de sua contribuição. Nesse contexto, sua produção posterior reitera a qualidade que o coloca entre os grandes nomes da poesia brasileira. Em Belo, belo, as tonalidades oscilantes entre o claro e o escuro concorrem para ratificar o que já fora tema de suas obras anteriores, mas, dessa vez, desenvolve-se a partir de tópicos que não concorrem 
para definir a melancolia do poeta nos termos do abismo onde o sofrimento mergulha. Assim, a tensão contida em idas e vindas, em movimentos bruscos que desestabilizam a já fragilizada existência do poeta, encontra um termo de equilíbrio. Isso corresponde ao instante em que o exercício da vida e da poesia chegam a um acordo. Daí o diapasão crítico de uma obra que dialoga consigo mesma, bem como com a de seus pares, desenvolver essa referência em "Mário de Andrade ausente" e "Resposta a Vinícius", poemas que reiteram essa posição:

E se pensarmos da poética reflexa à gênese de sua obra, veremos que a presença do biografo é ainda poderosa mesmo nos livros de inspiração absolutamente moderna. 0 adolescente mal curado da tuberculose persiste no adulto solitário que olha de longe o carnaval da vida e de tudo faz matéria para os ritmos livres do seu obrigado distanciamento. (BOSI, 1989, p. 410).

A poesia de Manuel Bandeira confirma-se como soma de elementos dispersos que dão origem ao que aparentemente não se constitui em assunto poético relevante, uma vez a isso corresponde a série de vicissitudes de uma existência que poderia ter sido interrompida, mas que encontra na poesia seu sentido verdadeiro. 0 ato de escrever poesia consiste na atividade precípua de quem se vê obrigado a abrir mão de tudo quanto os prazeres oferecem para contar dia após dia com a possibilidade do fim. Esse exercício ininterrupto lhe serve de tema, do mesmo modo que colabora para que o processo de construção do texto obedeça aos critérios inerentes à criação como uma espécie de remédio que combate as instâncias da morte que se aproximam. $\mathrm{O}$ artesanato poético de Manuel Bandeira diz respeito à observação arguta de quem busca cerzir o que se esfarrapou, ao recompor o tecido de que se constitui sua obra. Assim, a poesia tem como ponto de partida determinados núcleos de onde se dissemina seu processo de criação, em vista da precariedade de um mundo onde sua condição pessoal se insere como termo integrante. A medida das coisas que se dispersam para logo em seguida tornarem a fazer sentido são o meio que encontra para exercitar sua verve criativa.

A partir de presente tentativa de leitura, torna-se evidente o lugar único a ser ocupado pela poesia de Manuel Bandeira como um conjunto de sentido harmônico onde não se verificam desequilíbrios que sirvam como pretexto para que se estabeleça um rompimento com relação à sobriedade e à linearidade do que escreve. Pautada em elementos referentes ao teor estético de quem se exercita na leitura e na tradução de diferentes poetas, seu inquestionável talento acostuma-se ao convívio com a dimensão estética não apenas da poesia, mas também da pintura e da música como elementos capazes de lhe fornecer os instrumentos necessários à configuração de um estilo que só a ele pertence. Diante disso, sua poesia assume uma dimensão criativa que se faz representar por conta própria, sendo possível ao poeta abrir mão da radicalidade que determina os caminhos a serem seguidos pelo Modernismo para dialogar com a tradição. Essa posição a torna mentora de profundas transformações na ordem do que se apresentam em poemas como "Não 
sei dançar" e "Tragédia brasileira". Por isso, o homem desajeitado, que se define como alguém que engoliu um piano e deixou o teclado do lado de fora, em referência à proeminência de seus dentes, escreve poesia como que tenta reparar os estragos que a vida lhe provocou:

Embora Bandeira tenha sido - atingido na idade juvenil pelo pressagio da morte - dono daquela alegria circunspecta, daquele destaque participante que somente quem esteve "além" pode conhecer, foi ele próprio quem, na sua longa vida, soube fazer-se partícipe de toda experiência estética: do Simbolismo à Poesia Concreta, num jogo constante de experimentação artística conduzida sempre com extraordinária leveza e divertido pudor. (STEGAGNOPICCHIO, 2004, p. 492).

O plano de uma estética definida como capaz de situá-lo entre os maiores poetas do país faz de Manuel Bandeira alguém para além da condição de quem constrói um corpus significativo de sua obra. Por sua vez, a partir de um determinado período, passa a despreocupar-se cm relação às batalhas literárias que se seguem. Na condição de decano para quem esses enfrentamentos não se configuram em termo essencial, sua poesia passa a refletir acerca da finitude da vida, evidenciando a reflexão de quem teve, na sucessão dos dias, um desafio a ser superado. Não se trata mais de fazer versos como quem não sabe o que o amanhã lhe pode proporcionar, ou mesmo de encarar com ironia a doença e a morte, senão de entender o que representa a velhice e o termo final das coisas que se dispersam para nunca mais. Diante disso, a melancolia que se faz presente em alguns poemas, a exemplo de "Natal 64", significa o lugar da poesia como um lenitivo para a dor e o sofrimento de quem enfrenta as vicissitudes do tempo a partir de um tom menor que caracteriza o diapasão de uma voz mínima, quase imperceptível, que se apresenta em seus poemas.

\section{A CANTORIA E O EXPERIMENTO}

A instância derradeira da obra de Manuel Bandeira diz respeito ao momento em que publica Louvações (1948) e Mafuá do malungo (1948), onde reúne saudações aos amigos de forma sequencial, passando a limpo a lista de pessoas de seu convívio de poeta. Essas duas obras, no entanto, reiteram apenas a condição de uma obra in progress, não representando nenhum sentido transformador que venha a acarretar figurações inusitadas na obra de quem já produziu alguns dos melhores poemas do Modernismo. Assim, quase sexagenário, Manuel Bandeira presta-se a louvar os amigos, sendo Mafuá do malungo confeccionada na presa manual de João Cabral de Melo Neto, em tiragem reduzida. Nesses poemas, põe em evidência um rimário que o remete inevitavelmente à herança que recebera da poesia nordestina, 
através de alguns de seus cantadores populares, por meio de quadras rimadas, muitas delas em improvisos. Isso o faz portador de um saber que se expande para além do que ficara fixado na representação máxima do poeta engajado à campanha modernista. Essa atitude o torna responsável pela criação de poemas definitivos que concorreram para que o movimento ganhasse a dimensão do que se fez representar no tempo.

Há que se perceber, tanto em Louvações quanto em Mafuá do malungo, no desatar provisório do poeta modernista a abrir mão de uma luta que se situa em um período de trégua, na medida em que alguns dos mais importantes nomes da primeira fase seguiram caminhos diversos, no que se refere à renovação da poesia. Esse momento, por sua vez, reflete o equilíbrio de uma geração amadurecida, o que corresponde necessidade de a poesia expressar-se em manifestos contra a tradição simbolista-parnasiana, quando não passam a divergir uns dos outros. A partir da deflagração da Semana de Arte Moderna verifica-se sua condição de evento catalisador de profundas mudanças no conceito de poesia que se instaura. Desse modo, há que se pensar acerca do poeta como alguém para quem a poesia representa a própria vida, não sendo possível abrir mão de todas as suas condições de vir a se manifestar. Isso perpassa estilos variados, que vão do soneto e da redondilha ao improviso do martelo agalopado de cordelistas e cantadores. Por esse caminho, a poesia de Manuel Bandeira afirma-se na plenitude das formas a que consegue lançar mão com maestria:

Pode-se dizer de Manuel Bandeira, mais do que outro qualquer de seus confrades modernistas, que se transformou, ao longo de sua extensa carreira literária, para permanecer idêntico. Vale dizer: suas antenas captavam sinais em toda parte, absorviam-nos e transfundiam-nos em mensagens de beleza, mas sem alterar a substância de uma visão do mundo que se manteve fiel a si mesma, no decurso de meio século de elaboração poética. (MOISÉS, 2000, p. 421).

A poesia de Manuel Bandeira situa-se expressão bem-sucedida de quem consegue se multiplicar em diferentes formas da criação, não havendo como reiterar o que já fora perpetrado, em face de sua participação no que representou a hecatombe modernista. Assim, dedica-se a usufruir do prestígio inegável que sua obra passa a desfrutar nos últimos anos de sua vida, diante do que representa a sucessão de transformações que se efetivam como um sinal positivo do poder que a poesia exerce em sucessivas instâncias da cultura. Manuel Bandeira assume uma posição de distanciamento, no que tange ao papel de quem participou de importantes manifestações que revitalizaram a poesia brasileira. Por fim, lhe cabe $o$ lugar de quem toma parte no debate que torna a efervescer, no âmbito da criação poética, sendo eventualmente um articulador de ideias que assume posições em participação efetiva. Diante das transformações que o tempo determina à dinâmica da criação poética, sua tomada de posição corresponde às de um veterano que provisoriamente assume um posto destacado. 
No entanto, o surgimento da Poesia Concreta teria efetivamente levado Manuel Bandeira a não apenas lançar mão de sua condição de crítico, como do mesmo modo produzir tetos poéticos ao estilo dos concretistas, a partir da publicação de "Composições" e "Ponteio", que traduzem seu entusiasmo acerca do que se revela como uma incógnita para a maioria dos críticos e escritores que comparecem à Exposição Nacional de Arte Concreta, em São Paulo e no Rio de Janeiro. A partir da publicação da revista 0 Cruzeiro, que a chamou de o rock and roll da poesia, a Poesia Concreta traz à luz do debate uma geração preparada do ponto de vista crítico que desperta em Manuel Bandeira o interesse de vislumbrar em sua atividade uma renovação que não se percebia desde a Semana de Arte Moderna. Diante disso, não apenas se coloca de modo favorável à Poesia Concreta como também argumenta em favor de uma observação crítica que, segundo ele, se faz inevitável, uma vez que, mais que gostar ou não do que os concretistas produzem, se faz preciso entender a formulação teórica que apresentam:

Diante das palavras consteladas pelo uso de um planetarium fixo de significados e associações, Bandeira se comporta como um operador rebelde, que se insubordina contra as figuras sempre repetidas do estelário dado (frases feitas de domínio comum) e, subitamente (luciferinamente), procura recompor a seu arbítrio poético os desenhos semânticos articulados pelo uso, resgatar as estrelas-palavras de suas referências e das imagens estáticas que projetam. (CAMPOS, 2013, p. 111).

Em vista disso, Manuel Bandeira lança-se à aventura de produzir alguns objetos poéticos, a partir de sua enorme capacidade inventiva, o que o faz renovar seu repertório, do mesmo modo do que representou o simbolista de $A$ cinza das horas ter assumido uma posição crítica a partir de "Os sapos" como poema que busca desestabilizar a tradição. Por esse meio, reflete acerca da chamada Geração de 45 como um retrocesso às conquistas formais do Modernismo. Assim, ao classificá-la como 'geraçãozinha de 45", observa nesse movimento uma espécie de Noeparnasianismo de sentido retrogrado e conservador que busca corrigir os supostos excessos do Modernismo. Por sua vez, o surgimento da Poesia Concreta o estimula a produzir peças de feitura singular, o que do mesmo modo suscitaria o entusiasmo de quem se situa no cerne da discussão, a exemplo de Haroldo de Campos, que saúda o autor de "As três mulheres do sabonete Araxá" como um decano de várias lutas que se coloca ao lado dos concretistas, na dura batalha contra o conservadorismo que busca ocupar posições. Diante disso, do mesmo modo que concorre para o reconhecimento dos concretistas, Manuel Bandeira retorna a seu lugar de poeta e crítico, a partir da edição de Apresentação da poesia brasileira, obra por ele organizada.

Nos anos que antecedem sua morte, assiste com entusiasmo a publicação de sua poesia reunida no volume intitulado Estrela da vida inteira (1966), onde se incluem também seus Outros poemas. Neles podemos observar a reiteração da 
posição de um poeta que faz versos como que vive a vida a que lhe foi dado o direito de viver, reafirmando a noção de equilíbrio e contenção que marca sua trajetória como símbolo de uma profunda capacidade de pensar a partir da poesia. Assim, o poeta não apenas dela se serve para observar o mundo como, mas, do mesmo modo, a ela acrescenta elementos de fundamentação teórica de elevado valor. Ao situa-se como figura exponencial da poesia brasileira, a partir de uma obra de mérito inquestionável, Manuel Bandeira assume em seu último momento a posição de quem se utiliza da poesia para passar a limpo todo o seu processo de vida e criação. Por esse meio, concebe as respostas que ficaram por ser ditas, o que somente a poesia lhe poderia explicar. De posse dos instrumentos de que sempre dispôs para a construção de sua obra, Manuel Bandeira parece não se desesperar diante do tempo, na medida em que segue compondo seus poemas com a mesma vitalidade de um estreante, ainda que contando com a naturalidade que o faz concebê-los como que produz um vinho capitoso, de safra e sabor especiais.

\section{Referências}

ARRIGUCCI JR., Davi. Humildade, paixão e morte: a poesia de Manuel Bandeira. São Paulo: Cia. das Letras, 2003.

BANDEIRA, Manuel. Estrela da vida inteira. Rio de Janeiro: José Olympio, 1973.

BOSI, Alfredo. História concisa da Literatura Brasileira. São Paulo: Cultrix, 1989.

BRANDÃO. Roberto de Oliveira. Poética e vida em Bandeira. In: LOPES, Telê Porto Ancona. (Org.). Manuel Bandeira: verso e reverso. São Paulo: T.A. Queiroz, 1987, 22-28.

CAMPOS, Haroldo de. Metalinguagem e outras metas: ensaios de teoria e crítica literária. São Paulo: Perspectiva, 2013.

GOLDSTEIN, Norma. Do Penumbrismo ao Modernismo: o primeiro Bandeira e outros poetas significativos. São Paulo: Ática, 1983.

HOLANDA, Sérgio Buarque de. Trajetória de uma poesia. In: BRAYNER, Sônia. (Org.). Manuel Bandeira. Rio de Janeiro, Brasília: Civilização Brasileira, INL, 1980. p. 142-157.

MOISÉS, Massaud. A Literatura Brasileira através dos textos. São Paulo: Cultrix, 2000.

SODRÉ, Nelson Werneck. História da Literatura Brasileira: seus fundamentos econômicos. Rio de Janeiro: Civilização Brasileira, 1969. 
STEGAGNO-PICCHIO, Luciana. História da Literatura Brasileira. Rio de Janeiro: Nova Aguilar, 2004.

\section{Para citar este artigo}

VALENTE JÚNIOR, V. V. $\quad 0$ poeta das coisas pequenas: a trajetória de Mnuel Bandeira. Macabéa - Revista Eletrônica do Netlli, Crato, v. 9, n. 4, 2020, p. 239-250.

\section{O Autor}

VALDEMAR VALENTE JUNIOR é doutor em Ciência da Literatura pela UFRJ. Pós-Doutor em Literatura Brasileira pela UERJ. Professor da Universidade Estácio de Sá. 